\title{
Experimental Courses of Foreign Languages at the Department of Germanic Linguistics of the Adam Mickiewicz University at Poznań
}

\section{The assumptions of the courses}

New theories of foreign language teaching which have been recently developing violently have to be, first of all, verified. They cannot be verified during ordinary lessons in secondary schools or at the universities, because (1) both secondary schools and universities have strictly determined curricula, (2) new theoretical ideas cannot be applied to "mass" teaching without being practically tested under scientific guidance, and (3) some experiments which have to be done need special conditions. To the latter belong the courses the result of which is beforehand assumed negative, e.g. the verification of the theoretical assumption whether the group of learners should be integrated with regard to age and education. It is very important in teaching foreign languages outside school at all sorts of evening courses. The above said premise made it necessary to verify the theoretical principle of the methodology of foreign language teaching during special courses. Only after it we can try to test our assumptions within the secondary school or university curricula. The latter case is not a real experiment, but it is an "experimental" introducing of new methods into "mass" teaching. Our procedure may be compared with introducing a new medicine. Before a new method or medicine becomes widely used it has to be verified or tested under scientific guidance and observation.

The aim of the courses held by the Department of Germanic Linguistics (now taken over by the Institute of Applied Linguistics) was to gain some information about preliminary verification of different theoretical assumptions. They were to test certain assumptions in a complex way, i.e. each course was to give information about several problems at once. Their intention was to give answer to the most important questions. Scientific precision must have suffered, of course, i.e. testing could not have been founded on broad objective basis. But the results we obtained allowed us to see the direction in which the practical verification of theoretical assumptions should move. We have drawn some theoretical conclusions, too. Thus the courses of this kind accomplish another aim, namely, they render possible to draw theoretical conclusions in a vast range.

\section{Teaching staff}

The management of the courses had a lot of trouble with the teaching staff. Only a part of courses were held by people who were both theoretically and practically qualified for the post. Specialists are usually few in number. It should be remembered that only a native speaker has full practical qualifications to held 
experimental courses. There are not many non-native speakers who know a foreign language as their mother tongue. There was another problem with native speakers, their theoretical preparation for the job. Hence it was necessary to divide the task. The scientific part of the courses should be guided by a person with adequate linguistic preparation. The practical part should be done by a native speaker. And if we assume that a large number of Polish teachers were not prepared to take over the linguistic part, the ordinary type of courses was that a person who did the linguistic part did not do the practical part. It seems to me that in future this very type of courses will be the most possible to be held. It should be remembered that a scholar can often have very good methodological ideas based on research but he is not able to verify them in practice. For, firstly, he does not always speak well the language in question, secondly, he is not always a good teacher. Teaching may be compared with driving. With few exceptions everybody can drive strictly according to the rules, i.e. he does not disturb pedestrians, his passengers and his car. But among those drivers there are some who have special abilities in driving. Those are the drivers choice. The same applies to teachers of foreign languages. The modern didactic is to give the teacher the rules of correct teaching. The proper realization of these rules will depend on teacher's didactic talent and, partly, on the time of teaching. Not all scholars have an inborn didactic talent and only few of them have ever taught foreign languages. Thus it may happen that a scholar who has neither didactic talent nor has ever taught may put in practice the rules of correct teaching even worse than a medium-talented professional teacher. We propose, then, a cooperation between a scholar and a good teacher. The best teacher is, of course, a native speaker.

The above said teaching staff have to be, however, drilled beforehand. They have to get acquainted with premises of modern methods in general, and with scientific foundations of a given course in particular. Only in the latter case the cooperation will give desirable results. Our courses were experimental in this respect, too. They were a starting point to proper experimental courses. We have, nevertheless, gained some experience.

We had two native speakers for five courses. One of them (Harri Kirsch, M. A., from Berlin University) worked on both parts, i.e. practical and linguistic. Polish teachers held two experimental courses, namely, Miss Tertel, M.A. had a course in rehabilitation of the articulation basis for the first year students of German Philology in Warsaw, and Dr Kobylański from Poznań University had a course in English for children. The rehabilitation course was held for one year and gave very good results. Miss Tertel writes about these results in this volume of Glottodidactica. Recent superficially done tests proved, however, that the wrong pronunciation recurred. The conclusion is that the drilling and automation of correct pronunciation were not sufficient. This fact should be taken into consideration in other courses of that kind. Dr Kobylański's course has not yet come to an end.

This year the number of courses was reduced to three. Besides the above mentioned course held by Dr Kobylański there are two others, namely, a course in German held by Mrs Grucza, M.A., and a course in English held by Mrs Mroczyk. Mrs Grucza does the linguistic part, too.

The characteristics of the courses

As we have mentioned above the aim of the courses was not to solve any particular problem. They were to give preliminary information about verification of different new theoretical foundations, and in this respect they were successful. 
They were to last for one year. These were courses for beginners. They were held from many points of view, e.g. mastering of good foreign articulation, grammatical structures and vocabulary, unreflective oral reaction, age, education, etc.

\section{Preliminary results}

We cannot give final results at the moment. They are being analysed now. The courses were held for two years, from 1962 to 1963. Some results, as I have already mentioned, are published in this volume (Tertel, Kirsch). I shall draw attention only to the most interesting observations.

\section{The age of learners}

As I have mentioned above, one of the aims of the courses was to verify the theoretical assumption that the mastering of foreign articulation depends on age. The courses backed up this assumption. Children up to fifteen adopt the articulation easily and properly. The younger the child the faster this process is. Children after ten already try to adopt the articulation consciously. Hence they learn foreign pronunciation faster than younger children. It makes an impression that older children master the pronunciation easier. But it is an illusion. Children before ten learn the pronunciation more slowly than older ones, but finally they adopt it perfectly. Older children, i.e. children after ten cannot do it to such a degree. They at once perceive the foreign sounds with a maximum of articulatory precision but with the influence of the mother tongue, and finally, they need more time to adopt correct pronunciation. The interference of the native language starts working already by that time, and it grows stronger in case of fifteen years old children. The numbness of the circuit of building articulatory matrices starts at that time. The perceived sounds are attached to the matrices of the native language and the perception may be quite wrong.

Comparing the results of experimental courses for children till fifteen, young people between fifteen and twenty, people between twenty and thirty, thirty and forty, forty and fifty, we have come to the conclusion that the possibilities of adopting correct foreign pronunciation is in proportion to the age of learners, while fifteen years old children may master the articulation in one hundred per cent, by the fiftieth year of age the possibility is nearly nought.

Learning structures and vocabulary is a different thing. Children between seven and ten had a lot of trouble in learning certain grammatical structures. Children after ten did it faster. The same applies to the vocabulary. Therefore we postulate to test first learning of grammatical structures and vocabulary of the native language with childern up to the age of fifteen. There is hardly any literature on this subject. But this literature should be the starting point for writing detailed programmes of teaching children from this point of view. From our experiments we have drawn the following theoretical conclusion: Older people have more difficulties with what we call "closed structures" (pronunciation), while they learn "open structures" (syntax, and especially the lexical system) easier. It agrees with theoretical premises, namely, that the circuit of building word structures in the native language works as long as we live. It never grows numb. We know perfectly well that we shall never learn all open structures of a foreign language since they are too numerous. Closed structures of a language are not so numerous, e.g. sounds and their distribution. Their difficulty lies in quality, and the circuit of building sound matrices of the native language grows numb with the age. 
We draw the final conclusion: teaching of foreign languages should start between the seventh and the fifteenth year of life. People after twenty five should be troubled with drills in order to make them pronounce the sounds of a foreign language perfectly. Few of them will, and to some extent only, acquire proper pronunciation. Therefore in the latter case more time should be devoted for learning open structures. Admitting people after twenty to schools of foreign languages is not, from this point of view, advisable. Probably only a small number of them can finally learn proper pronunciation. It is still worse to admit people with bad pronunciation. They need a special rehabilitation treatment of their pronunciation. It is a very difficult problem since bad speech habits always tend to recur.

The results of our experimental courses show that the manuals of foreign languages should be differentiated according to the age. The material in these manuals will have to be arranged differently for people between twenty and thirty and differently for people between forty and fifty.

Our experimental researches and generalizations concerning the influence of age on learning foreign languages do not exhaust the problem. Our results should be verified by other scholars.

Age as a decisive factor in detailed methodology of foreign language teaching was first deduced statistically. We have tested at random the degree of adopting English pronunciation by Polish emigrants. Then we have established theoretical foundations of our statistic data and verified them during our experimental courses. We shall be very glad to exchange experiences with other scholars working on these problems.

We should like to draw attention to another symptom of influence of age on detailed methodology of foreign language teaching. Young people before eighteen did not feel the lack of written texts. All our courses were held without manuals. We applied the conversational method. The conversations were not taken down. Our intention was to give good pronunciation as a basic store of a foreign language. Older people, however, wanted a written basis of a language. They wanted to learn a foreign language on written or printed texts. It is quite understandable from the theoretical point of view. We adopt a foreign language as a structure parallel to the native language. People after twenty, especially the educated ones, who were in majority at our experimental courses segmented the units of the native language on the basis of written segmentation. It has to be taken for granted that their basic store of semantic morphemes was based on the graphics. At least, the graphics exerted strong influence on the sound store of morphemes. It should not surprise anybody that it was difficult for them to build matrices and the store of concrete language morphemes on the basis of pronunciation. Their ears did not catch different foreign sounds and they could not, of course, do proper morpheme segmentation. These difficulties made them nervous. But with the help of a printed text the difficulties were overcome. We know that it is easier to learn a written text than a spoken one. In this case there is a danger that the graphics should influence the pronunciation according to the graphic rules of the native language. But at this age it is not so dangerous as by younger people. Older people, as we pointed above, have but a limited possibility of acquiring proper pronunciation. From these considerations we draw the conclusion that teaching people after thirty we should start from the written text or, at least, at the end of a lesson the teacher should write on the blackboard the text presented oraly before (if there is no manual). But disregarding the age learning 
of a foreign language should always begin with conversations. The experiments showed that it was a big stimulus and gave the lesson a motivation.

At our courses we postulated four-segment conversations. Their aim was to make the conversation more vivid. By questions and answers, i.e. two-segment conversations, the person who asks controls the conversation. It looks like an examination or a try. In four-segment conversations both partners are on equal terms. Such a conversation consists of question-answer-question-answer, i.e. he who asks the question must in turn answer his partner's question. This system may be introduced even from the second lesson on. Such lessons make an impression of natural conversation. Later three people may join one conversation. The intention of this method is to give one of the partners some time to prepare his question. This method makes all partners take an active part in the conversation, it brings the lesson closer to ordinary conditions. A language should be taught in situations it will be used. We have to come in practice as near as possible to this ideal postulate. A four-segment text partly solves the above mentioned methodological postulate. Our experiments showed that learners liked four-segment texts. But teachers fell into old habits. They gave and practised two-segment texts. We could not overcome these difficulties, teachers have their old didactic habits. Children had some difficulty with four-segment texts, especially when the segments were long. But with the age the problem becomes easier and easier. Learners upwards the age of fifteen liked this way of conversation best.

(To be continued in the next volume) 